\title{
Effect of Gonadal Hormones on Colonic Contractile Activity in Albino Rats
}

\author{
Mohamad Yosof Rezk \\ Physiology Unit, Basic Medical Sciences Department, College of Medicine and Medical Sciences in Unaizah, Qassim \\ University, Unaizah, KSA
}

Email address:

myr777777777@yahoo.com

\section{To cite this article:}

Mohamad Yosof Rezk. Effect of Gonadal Hormones on Colonic Contractile Activity in Albino Rats. American Journal of Internal Medicine. Vol. 5, No. 2, 2017, pp. 26-36. doi: 10.11648/j.ajim.20170502.13

Received: March 3, 2017; Accepted: March 27, 2017; Published: April 17, 2017

\begin{abstract}
Sex differences were reported in Irritable Bowel Syndrome. We aimed to demonstrate the effect of gonadal hormones on colonic contractile activity. In this study, we performed in vitro measurements of colonic contractile activity in longitudinal smooth muscle strips of female and male Albino rats. After administration of a gonadal hormone (estrogen (EST), progesterone (PROG) and testosterone (TEST)) or ethanol (ETH) solution as control, stimulation with acetylcholine (ACh) or inhibition with norepinephrine (NE) was performed. We found that increasing doses of EST resulted in a stepwise inhibition of SCCA in both sexes and inhibited the ACh effect in females. Similarly, high dose PROG inhibited SCCA in females. TEST inhibited SCCA in males but not Ach induced contractions. TEST reduced the inhibitory effect of NE in female rats. In conclusion, exposure of colonic smooth muscle strips to gonadal hormones led to sex-dependent changes in SCCA and modified the response of smooth muscle strips to both pro-contractile and anti-contractile neurotransmitters.
\end{abstract}

Keywords: Colonic Smooth Muscle, Estrogen, Bowel Disorders, Gonadal Hormones, Irritable Bowel Syndrome, Motility

\section{Introduction}

Irritable bowel syndrome (IBS) is the most common functional gastrointestinal disorder associated with altered stool habits and chronic abdominal pain without evidence of specific structural or biochemical abnormalities [1]. Females represent up to two thirds of the IBS patients $[2,3]$. The exact etiology and pathophysiological mechanisms associated with these bowel disorders remain incompletely understood [4]. Various pathophysiological mechanisms [5] have been postulated including visceral afferent hypersensitivity $[6,7]$ inflammation $[8,9]$ and alteration in gastrointestinal motility $[10,11]$. Chang and Heitkemper, reported that a gender ratio of patients who seek health care for IBS and other functional bowel disorders is calculated 2-2.5: 1 of women to men or even 3-4: 1 [12]. The reasons for these gender differences are still controversial involving differences in stress reactivity, inflammatory responses and response to pain and sexual hormones [13, 14]. Heitkemper described periodical changes in ovarian hormones throughout the menstrual cycle simultaneously accompanied by alterations in symptom intensity [15]. In 2006, Cui et al. showed that peripheral blood estrogen levels in women and testosterone levels in males suffering from IBS were lower than in healthy individuals [14]. In a study with rats, the colonic transit during the phases of the estrous cycle with increased estrogen and progesterone levels was reduced [16]. Gonenne et al. found a significant acceleration of colonic transit by micronized progesterone in postmenopausal women [17]. Hogan et al. showed that the motility of human colonic smooth muscle decreased in response to superfusion with estrogen [18]. These observations support the hypothesis that IBS might be associated with a sexual hormone disorder. For this Background, the aim of the present study was to demonstrate the effect of gonadal hormones on colonic contractile activity and thus to a better understanding of the development of IBS and its gender distribution. In our study, we aimed to compare the spontaneous colonic contractile activity (SCCA) of female and male Albino rats, Measure the effects of gonadal hormones estradiol (EST), progesterone (PROG) and testosterone (TEST) on SCCA. Finally, to determine the acute effect of these gonadal hormones on the colonic contractile response (CCR) to acetylcholine (ACh) and norepinephrine (NE). 


\section{Materials and Methods}

\subsection{Animals and Tissue Collection}

Female $(n=6)$ and male $(n=6)$ Albino rats (11-13 weeks old, 180-220 g) were included in this study obtained from the College of Agriculture and Veterinary medicine, Qassim university, KSA. Rats were housed in a 12: 12-h light-dark cycle at $25 \pm 2{ }^{\circ} \mathrm{C}$, and had free access to tap water and commercial rat chow for 7 days for acclimatization before entering the study. All experiments were performed in accordance with the Institutional guidelines for the Care and Use of Animals for Scientific Purposes.

\subsection{Drugs and Chemicals}

(1) Modified Krebs-Ringer's bicarbonate solution: sodium chloride: $118.3 \mathrm{mmol} \mathrm{1-1,} \mathrm{potassium} \mathrm{chloride:} 4.7 \mathrm{mmol} \mathrm{l-}$ 1, calcium chloride: $2.5 \mathrm{mmol} 1-1$, potassium phosphate: $1.2 \mathrm{mmol} 1 \mathrm{-1}$, sodium bicarbonate $2.5 \mathrm{mmol} 1-1$, calcium disodium edetate: $0.26 \mathrm{mmol} 1-1$, magnesium sulfate: 2.5 mmol 1-1, glucose: $11.1 \mathrm{mmol}$ 1-1.

(2) Estradiol, progesterone, testosterone, acetylcholine and norepinephrine were purchased from Sigma trade company, Cairo, Egypt.

\subsection{Equipment}

(1) Organ bath: 63100 this apparatus for experimentation to investigate the activity of colonic strips.

(2) Kymograph and Stimulator- 10550- Bioscience.

(3) The lever: Remote release fixit-811-50100-0 bioscience- Palmer Washington.

\subsection{Methods}

The rats were killed by decapitation and the colon was excised. After wash with $0.9 \% \mathrm{NaCl}$, the colon was first equilibrated in Modified Krebs-Ringer's bicarbonate solution and bubbled with $95 \% \mathrm{O}_{2} / 5 \% \mathrm{CO}_{2}$ for 1 hour. The mesenteric tissue was cut out. In a second step, segments of colon with a length of $6 \mathrm{~cm}$, were taken and mounted in small volume (50 $\mathrm{ml}$ ) tissue bath in Modified Krebs-Ringer's bicarbonate solution. The temperature of the organ bath was kept at $36.5^{\circ} \mathrm{C}$, whereas the $\mathrm{pH}$ of the solution was kept between 7.357.45. $70-80 \%$ of the colon segments developed repetitive peristaltic contractions and were used in our experiments. Segments that did not show regular contractions were discarded. After 20-min control period, the test drug was added to the organ bath and a 10-min test period was recorded.

\subsection{Measurement of Spontaneous Contractions}

The muscle strips were suspended vertically in organ bath filled with a modified Krebs- Ringer's bicarbonate solution. Muscle strip was tied with cotton threads, one end to a fixed pin in the aerator of the bath and the other to an ink writing lever. Isometric contractions of colonic strips were monitored under constant passive force of $1.0 \mathrm{~g}$., this tension was maintained throughout the experimental protocol. This resting tension has been shown to develop maximum active tension in albino rat colon. The mechanical activity of the longitudinal muscle strips was measured isometrically with a calibrated force displacement transducer.

\subsection{Experimental Protocol}

The muscle strips were left for approximately 20 minutes equilibration period with several washouts of the bath solution. After equilibration with resting tension, SCCA was measured for 10 minutes in each muscle strip.

All experiments are done in the following order (male and female rats):

a). Each muscle strip will act as control in presence of Ethanol.

b). Dose response curve for the effect of EST (Rising doses of EST $(100 \mathrm{nM} / 1 \mathrm{uM} / 10 \mathrm{uM})$ were administered to the organ baths) on SCCA to determine the effect and to take the maximal dose for further experiments

c). Effect of EST (10 uM) on SCCA then EST with Ach induced contraction.

d). Effect of NE on SCCA then EST with NE

e). Effect of PROG (10 uM) on SCCA then PROG with ACH

f). Effect of NE on SCCA then PROG with NE.

g). Effect of TEST ( $10 \mathrm{uM})$ on SCCA then TEST with ACH

h). Effect of NE on SCCA then TEST with NE.

All hormones diluted in $70 \%$ ethanol.

\subsection{Change in Basal Tone}

The change in basal tone in the immediate 10 -min period after tissue incubation with the different agents was expressed as the percentage of the mean amplitude of the spontaneous contractions occurring in the 10 -min period preceding the addition of the agents. Basal tone is defined as the lowest point (baseline) of the spontaneous contractions before the application of the agents. The amplitude of the spontaneous contractions was chosen because it expresses the contractile potential of each colonic strip. The change in basal tone was calculated using the formula: $\chi=\beta / \alpha \times 100$ [19], where $\chi$ is the percentage change in the basal tone, $\alpha$ is the mean amplitude of the spontaneous colonic contractions, and $\beta$ is the mean values of the distance of the lower parts of the induced contractions from the curve initial baseline.

\subsection{Frequency of Colonic Contractility}

In a 10-min period after tissue incubation with the agent was expressed as the change in the sum of spontaneous contractions occurring in a period of 10-min before application of the agents.

\subsection{The Amplitude of Colonic Contractility}

Was defined as the value of the distance of the highest point and the initial baseline of the evoked contractility in a period of 10-min after the application of each agent.

\subsection{Statistical Analysis}

The computer was used in statistical analysis (SPSS 
version 14 for windows). All data were expressed as mean \pm Standard Error of mean (SEM). We used paired t. test to detect significant differences between two means of the same muscle strips before and after the drug. We used also one way ANOVA test to detect significant differences between different groups. Significance was detected when $\mathrm{P} \leq 0.05$

\section{Results}

Table 1, Figure 1 and 2: show that Estrogen caused a very highly significant inhibitory effect on amplitude of SCCA in all doses $(\mathrm{p}<0.001)$. This inhibitory effect was found to be dose dependent $(\mathrm{r}=-0.98)$.

Table 1. The effect of different doses of EST on amplitude of SCCA described by centimeters (Dose response curve).

\begin{tabular}{llllll}
\hline & Control & EST 100 nM & EST 1 uM & EST 10uM & EST 100uM \\
\hline 1 & 10 & 2.5 & 1.5 & 0.8 & 0 \\
2 & 6 & 1.5 & 0.5 & 0.2 & 0 \\
3 & 8 & 2 & 1 & 0.5 & 0 \\
4 & 6 & 1.5 & 0.5 & 0.2 & 0 \\
5 & 8 & 2 & 1 & 0.5 & 0 \\
6 & 10 & 2.5 & 1.5 & 0.8 & 0 \\
$\overline{\mathrm{X}}$ & 8 & 2 & 1 & 0.5 & 0 \\
$\pm \mathrm{SE}$ & 0.73 & 0.18 & 0.18 & 0.10 & 0 \\
$\mathrm{tt}$ & $10.95 * * *$ & $12.78^{* * *}$ & $12.08^{* * * *}$ & \\
\hline
\end{tabular}

*** Highly significant $(\mathrm{p}<0.01)$.

Table 2 and Figure 3: show that EST inhibited significantly the contractile effect of $\mathrm{ACH}$ :

Table 2. The effect of $A C H$ and ACH with EST on amplitude of SCCA described by centimeters in Female rats.

\begin{tabular}{llll}
\hline & SCCA & ACH 20 uM & EST100 uM +ACH20 uM \\
\hline 1 & 0.2 & 1.6 & 1 \\
2 & 0.2 & 1.3 & 1.3 \\
3 & 0.7 & 2 & 2 \\
4 & 1.4 & 3 & 3 \\
5 & 1.6 & 2.5 & 2.5 \\
6 & 0.5 & 1.5 & 1 \\
$\bar{X}$ & 0.76 & 1.98 & 1.80 \\
\pm SE & 0.24 & 0.26 & 0.34 \\
$t t$ versus control & $0.006^{* *}$ & \\
$t t$ versus ACH & $0.03^{*}$ & & \\
\hline
\end{tabular}

* Significant $(\mathrm{p}<0.05)$.

** Highly significant $(\mathrm{p}<0.01)$.

- Non significant $(\mathrm{p}>0.05)$

Table 3. The Effect of PROG on amplitude of SCCA described by centimeters.

\begin{tabular}{lll}
\hline No & SCCA & PROG \\
\hline 1 & 2.5 & 0.4 \\
2 & 1.7 & 1 \\
3 & 1.5 & 0.3 \\
4 & 1.7 & 0.5 \\
5 & 3 & 1.5 \\
6 & 2.8 & 1.6 \\
$\bar{X}$ & 2.2 & 0.88 \\
\pm SE & 0.26 & 0.23 \\
tt versus control & $6.97 * *$ & \\
\hline
\end{tabular}

** Highly significant $(\mathrm{p}<0.01)$.
Table 4. The Effect of NE and NE with TEST on amplitude of SCCA in Female rats.

\begin{tabular}{llll}
\hline No & SCCA & NE & NE+TEST \\
\hline 1 & 2.8 & 1 & 2.8 \\
2 & 3 & 2.2 & 3 \\
3 & 1.5 & 0.2 & 1.5 \\
4 & 2.5 & 0.8 & 2.5 \\
5 & 1.6 & 0.5 & 1.6 \\
6 & 2 & 0.4 & 2 \\
$\bar{X}$ & 2.23 & 0.85 & 2.23 \\
\pm SE & 0.25 & 0.29 & 0.25 \\
tt versus control & $8.759 * *$ & & \\
tt versus NE & & $8.759 * *$ & \\
\hline
\end{tabular}

** Highly significant

Table 5. The Effect of NE and NE with TEST on amplitude of SCCA in male rats.

\begin{tabular}{llll}
\hline No & SCCA & NE & NE+TEST \\
\hline 1 & 2.75 & 1.5 & 1.5 \\
2 & 3.5 & 0.7 & 0.7 \\
3 & 2 & 1 & 0.8 \\
4 & 3.5 & 1.5 & 1.5 \\
5 & 2 & 1 & 1 \\
6 & 3 & 1 & 1 \\
$\bar{X}$ & 2.79 & 1.11 & 1.08 \\
\pm SE & 0.27 & 0.13 & 0.14 \\
tt versus control & $5.72 * *$ & & $6.12^{* *}$ \\
tt versus NE & & $1.00^{-}$ & \\
\hline
\end{tabular}

$* *$ : Highly significant $(\mathrm{p}<0.01)$.

-: Non significant $(\mathrm{p}>0.05)$

Table 6. the Effect of NE and NE with PROG on amplitude of SCCA described by centimeters: PROG augmented the inhibitory effect of NE on colonic contractions.

\begin{tabular}{llll}
\hline No & SCCA & NE & NE+PROG \\
\hline 1 & 1.2 & 0.25 & 0.1 \\
2 & 2.7 & 1.7 & 0.5 \\
3 & 3 & 1 & 0.7 \\
4 & 2.9 & 0.3 & 0.2 \\
5 & 1.5 & 0.6 & 0.3 \\
6 & 2.2 & 1.3 & 0.9 \\
$\bar{X}$ & 2.25 & 0.85 & 0.45 \\
\pm SE & 0.3 & 0.23 & 0.12 \\
tt versus control & $4.67^{* *}$ & & $6.47^{* *}$ \\
tt versus NE & & $2.48^{*}$ & \\
\hline
\end{tabular}

*: Significant $(\mathrm{p}<0.05)$. ** Highly significant $(\mathrm{p}<0.01)$.

Table 7. The Effect of different doses of EST on frequency of SCCA (in 10minutes period).

\begin{tabular}{llllll}
\hline & Control & $\begin{array}{l}\text { EST 100 } \\
\text { nM }\end{array}$ & $\begin{array}{l}\text { EST 1 } \\
\text { uM }\end{array}$ & $\begin{array}{l}\text { EST } \\
\text { 10Um }\end{array}$ & $\begin{array}{l}\text { EST } \\
\mathbf{1 0 0 u}\end{array}$ \\
\hline 1 & 12 & 8 & 4 & 3 & 0 \\
2 & 10 & 6 & 3 & 2 & 0 \\
3 & 7 & 5 & 2 & 1 & 0 \\
4 & 9 & 6 & 3 & 2 & 0 \\
5 & 10 & 7 & 4 & 3 & 0 \\
6 & 6 & 4 & 2 & 1 & 0 \\
$\bar{X}$ & 9 & 6 & 3 & 2 & 0 \\
\pm SE & 0.89 & 0.57 & 0.36 & 0.36 & 0 \\
tt versus control & $8.21 * *$ & & $10.39 * *$ & $12.12 * * *$ & \\
\hline
\end{tabular}

$* *$ Highly significant $(\mathrm{p}<0.01)$.

$* *$ Very Highly significant $(\mathrm{p}<0.001)$ 
Table 8. Effect of TEST and TEST + ACH on frequency of SCCA.

\begin{tabular}{llll}
\hline No & SCCA & TEST & TEST+ACH \\
\hline 1 & 16 & 15 & 16 \\
2 & 12 & 10 & 12 \\
3 & 11 & 10 & 11 \\
4 & 15 & 13 & 15 \\
5 & 22 & 19 & 22 \\
6 & 18 & 17 & 18 \\
$\bar{X}$ & 15.66 & 14 & 15.66 \\
\pm SE & 1.64 & 1.5 & 1.64 \\
$t t$ versus control & $5.00 * *$ & & SE of the difference $=0$ \\
tt versus TEST & & $5.00 * *$ & \\
\hline
\end{tabular}

** Highly significant $(\mathrm{p}<0.01)$

Table 9. Effect of NE and NE with TEST on frequency of SCCA (in female rats).

\begin{tabular}{llll}
\hline & SCCA & NE & NE+TEST \\
\hline 1 & 14 & 13 & 14 \\
2 & 12 & 11 & 12 \\
3 & 4 & 3 & 4 \\
4 & 7 & 5 & 6 \\
5 & 15 & 10 & 15 \\
6 & 10 & 7 & 10 \\
$\bar{X}$ & 10.33 & 8.16 & 10.16 \\
\pm SE & 1.72 & 1.55 & 1.79 \\
$t t$ versus control & $3.31^{*}$ & & $1.00^{-}$ \\
$t t$ versus NE & & $2.9 *$ & \\
\hline
\end{tabular}

*: Significant $(\mathrm{p}<0.05)$

** Highly significant $(\mathrm{p}<0.01)$.

-: Non significant $(\mathrm{p}>0.05)$

Table 10. The Effect of PROG and ACH with PROG on frequency of SCCA (in 10-minutes period).

\begin{tabular}{llll}
\hline & SCCA & PROG & PROG+ACH \\
\hline 1 & 8 & 7 & 8 \\
2 & 8 & 6 & 8 \\
3 & 21 & 18 & 21 \\
4 & 20 & 15 & 20 \\
5 & 15 & 12 & 15 \\
6 & 10 & 8 & 10 \\
$\bar{X}$ & 13.66 & 11 & 13.66 \\
\pm SE & 2.4 & 1.96 & 2.4 \\
$t t$ versus control & $4.78 * *$ & & Standard error of difference $=0$ \\
tt versus PROG & & $4.78 * *$ & \\
\hline
\end{tabular}

** Highly significant $(\mathrm{p}<0.01)$.

Table 11. The Effect of NE and NE with TEST on frequency of SCCA in male rats: (in 10-minutes period).

\begin{tabular}{llll}
\hline & SCCA & NE & NE+TEST \\
\hline 1 & 14 & 11 & 11 \\
2 & 18 & 12 & 12 \\
3 & 13 & 5 & 5 \\
4 & 10 & 9 & 9 \\
5 & 16 & 14 & 14 \\
6 & 12 & 9 & 9 \\
$\bar{X}$ & 13.83 & 10 & 10 \\
\pm SE & 1.16 & 1.26 & 1.26 \\
$t t$ versus control & $3.55^{*}$ & & $3.55^{*}$ \\
$t t$ versus NE & & The standard error of the difference= zero. \\
\hline
\end{tabular}

*: Significant $(\mathrm{p}<0.05)$.
Table 12. Effect of different doses of EST on\% change of basal tone of SCCA.

\begin{tabular}{lllll}
\hline & EST 100 nM & EST 1 uM & EST 10Um & EST 100uM \\
\hline 1 & -60 & -100 & -140 & -140 \\
2 & -64 & -95 & -150 & -150 \\
3 & -55 & -75 & -130 & -130 \\
4 & -60 & -60 & -100 & -100 \\
5 & -75 & -85 & -130 & -130 \\
6 & -50 & -70 & -110 & -110 \\
$\bar{X}$ & -60.66 & -80.83 & -126.66 & -126.66 \\
\pm SE & 3.48 & 6.24 & 7.6 & 7.6 \\
ANOVA & $13.58 * * *$ & & & \\
\hline
\end{tabular}

***: Very highly significant.

Table 13. Effect of EST and EST with EST + ACH on basal tone of SCCA.

\begin{tabular}{lll}
\hline & EST & EST+ACH \\
\hline 1 & -140 & -10 \\
2 & -150 & -15 \\
3 & -130 & -5 \\
4 & -100 & 0 \\
5 & -130 & -5 \\
6 & -110 & 0 \\
$\overline{\mathrm{X}}$ & -126.66 & -5.83 \\
$\pm \mathrm{SE}$ & 7.6 & 2.38 \\
$\mathrm{tt}$ & $13.39 * *$ & \\
\hline
\end{tabular}

**: Highly significant.

Table 14. The Effect of NE and NE+EST on SCCA.

\begin{tabular}{lll}
\hline & NE & NE+EST \\
\hline 1 & -40 & -40 \\
2 & -50 & -50 \\
3 & -30 & -30 \\
4 & -20 & -20 \\
5 & -30 & -30 \\
6 & -10 & -10 \\
$\bar{X}$ & -30 & -30 \\
\pm SE & 5.77 & $5.77-$ \\
\hline
\end{tabular}

-: insignificant.

Table 15. The Effect of $N E$ and $P R O G+N E$.

\begin{tabular}{lll}
\hline & NE & PROG+NE \\
\hline 1 & -140 & -145 \\
2 & -150 & -160 \\
3 & -130 & -130 \\
4 & -100 & -110 \\
5 & -130 & -135 \\
6 & -110 & -110 \\
$\overline{\mathrm{X}}$ & -126.66 & -131.66 \\
$\pm \mathrm{SE}$ & 7.6 & 8.02 \\
$\mathrm{Tt}$ & $2.7^{-}$ & \\
\hline
\end{tabular}

-: insignifigant. 
Table 16. Effect of NE and NE with TEST on basal tone of SCCA.

\begin{tabular}{lll}
\hline & NE & NE+TEST \\
\hline 1 & -110 & -100 \\
2 & -140 & -120 \\
3 & -120 & -110 \\
4 & -110 & -100 \\
5 & -140 & -130 \\
6 & -150 & -140 \\
$\overline{\mathrm{X}}$ & -128.33 & -116.66 \\
$\pm \mathrm{SE}$ & 7.03 & 6.66 \\
$\mathrm{Tt}$ & $7 * *(\mathrm{P}=0.0009)$ & \\
\hline
\end{tabular}

**: Highly significant.

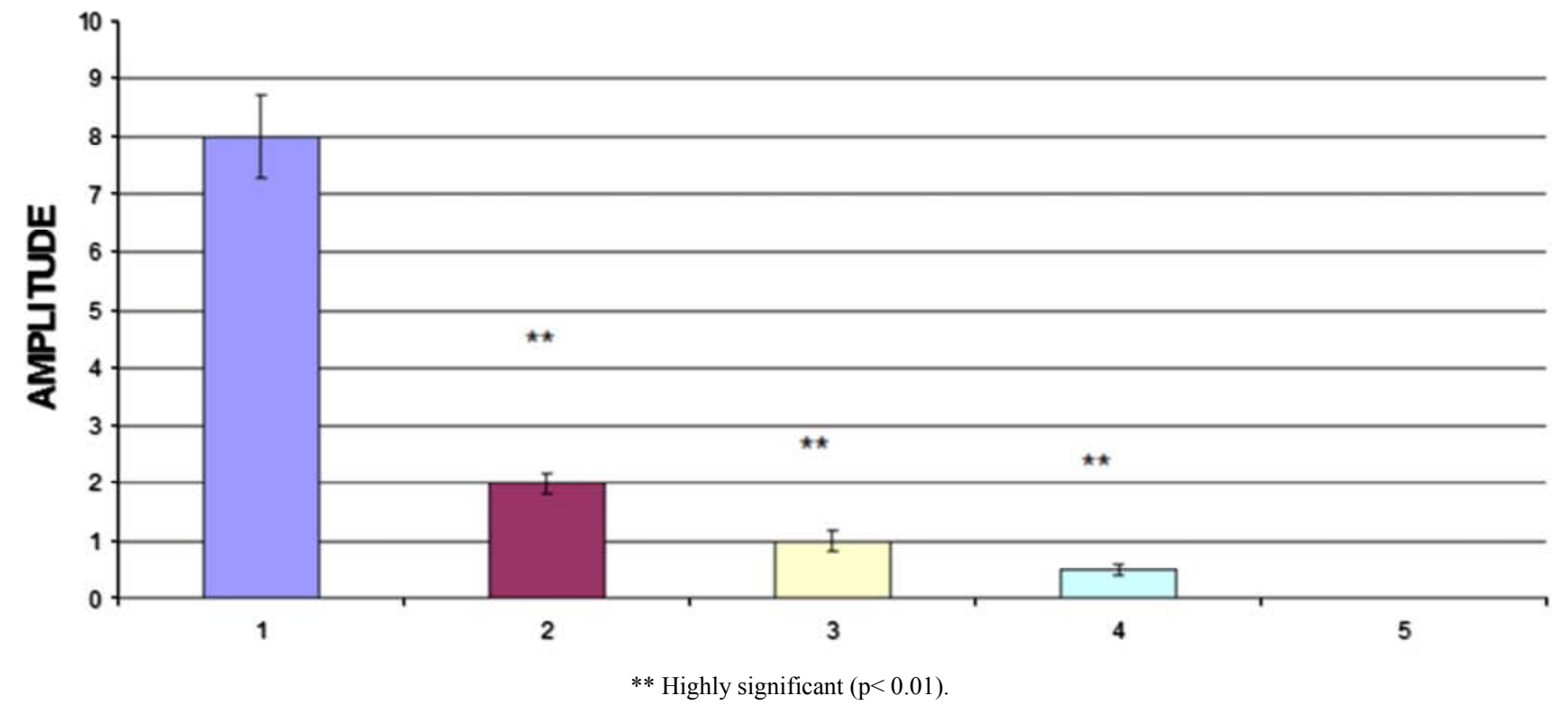

Figure 1. Show that Estrogen caused a very highly significant inhibitory effect on amplitude of SCCA in all doses ( $p<0.001)$. This inhibitory effect was found to be dose dependent $(r=-0.98)$.

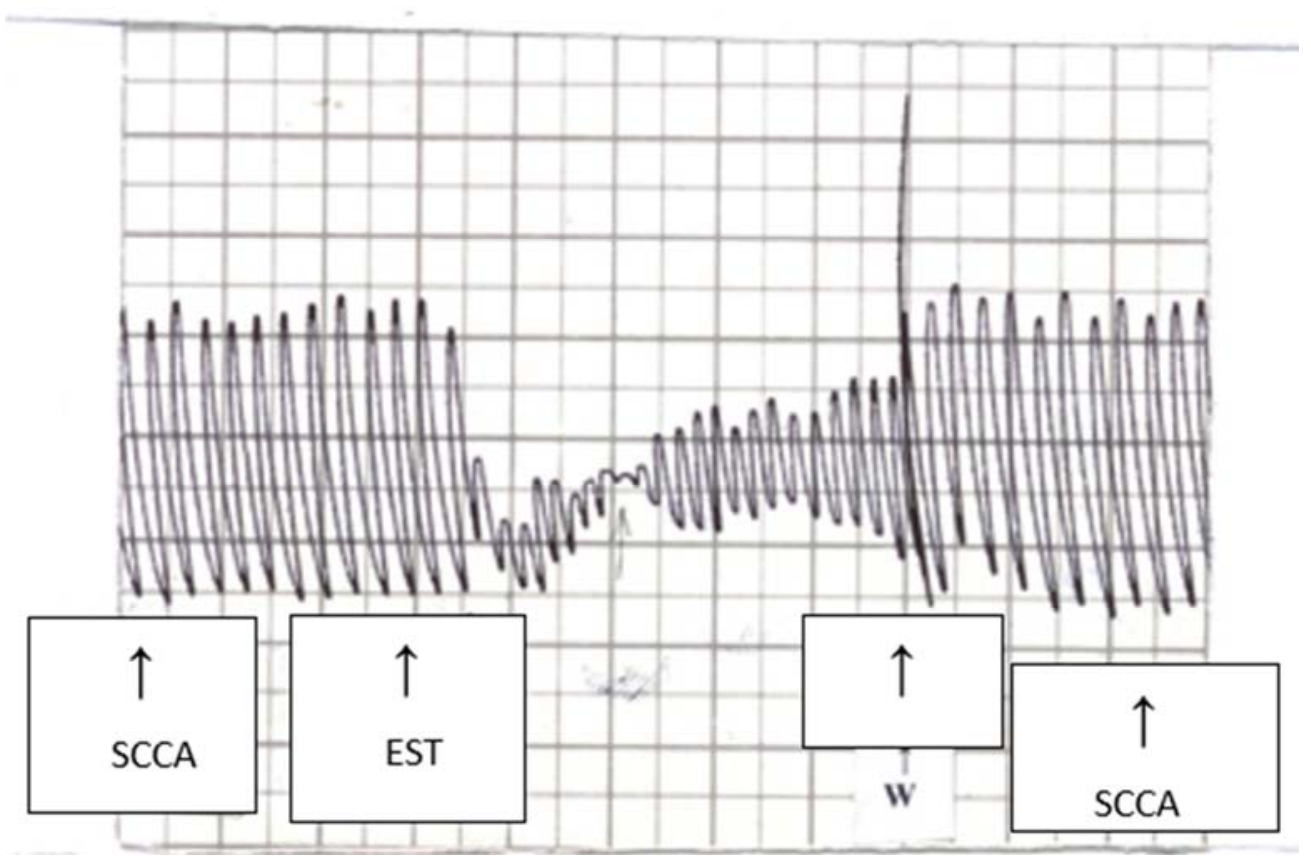

Figure 2. Effect of estrogen on SCCA (Spontaneous Colonic Contractile Activity) in male rats. 


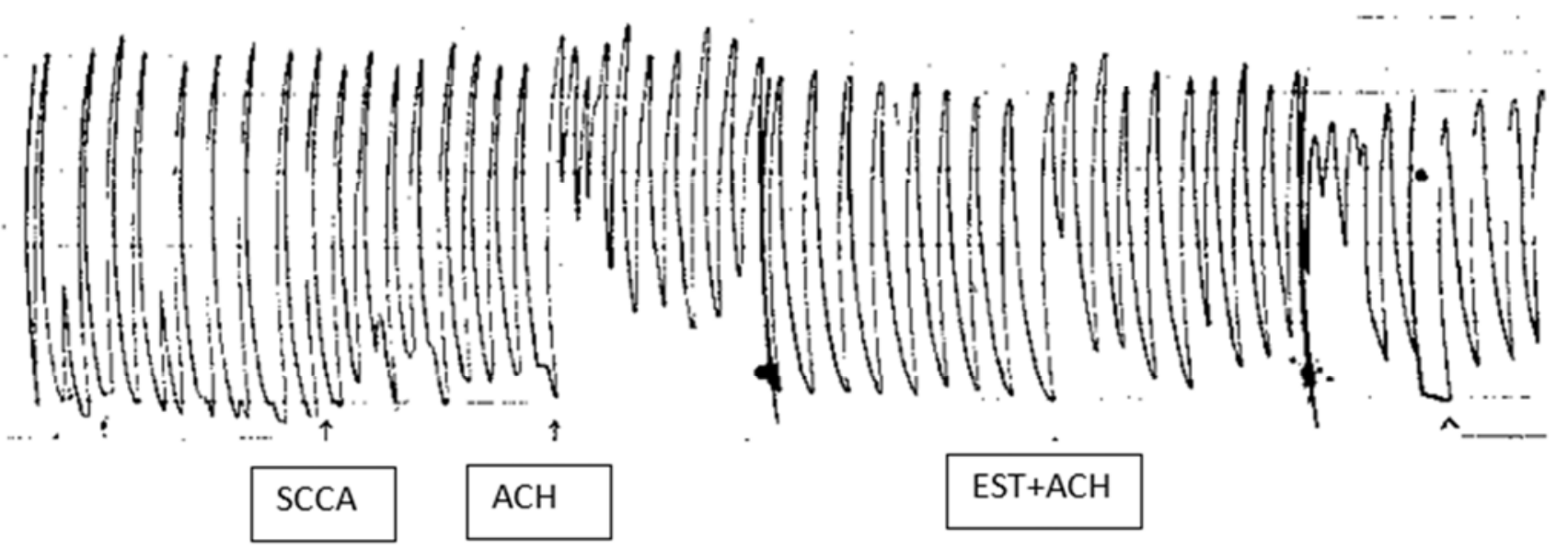

Figure 3. The effect of ACH and ACH with EST on SCCA in Female rats.

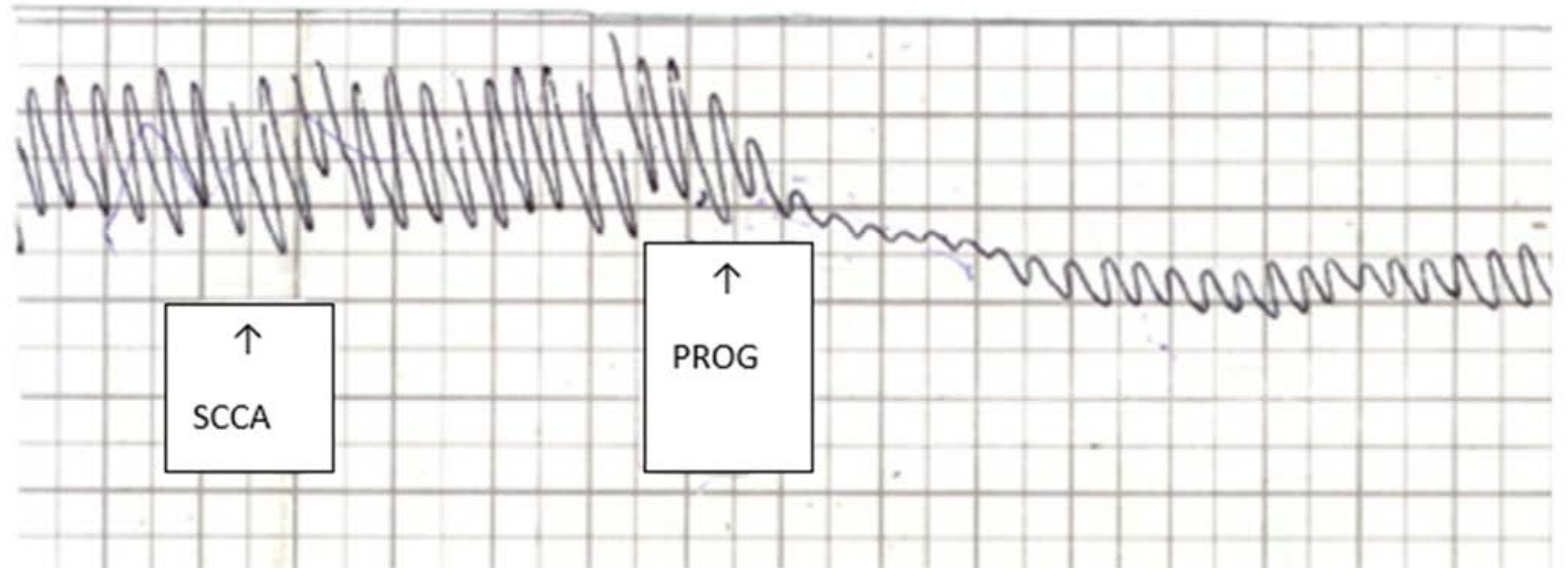

Figure 4. Show the effect of prog on scca.

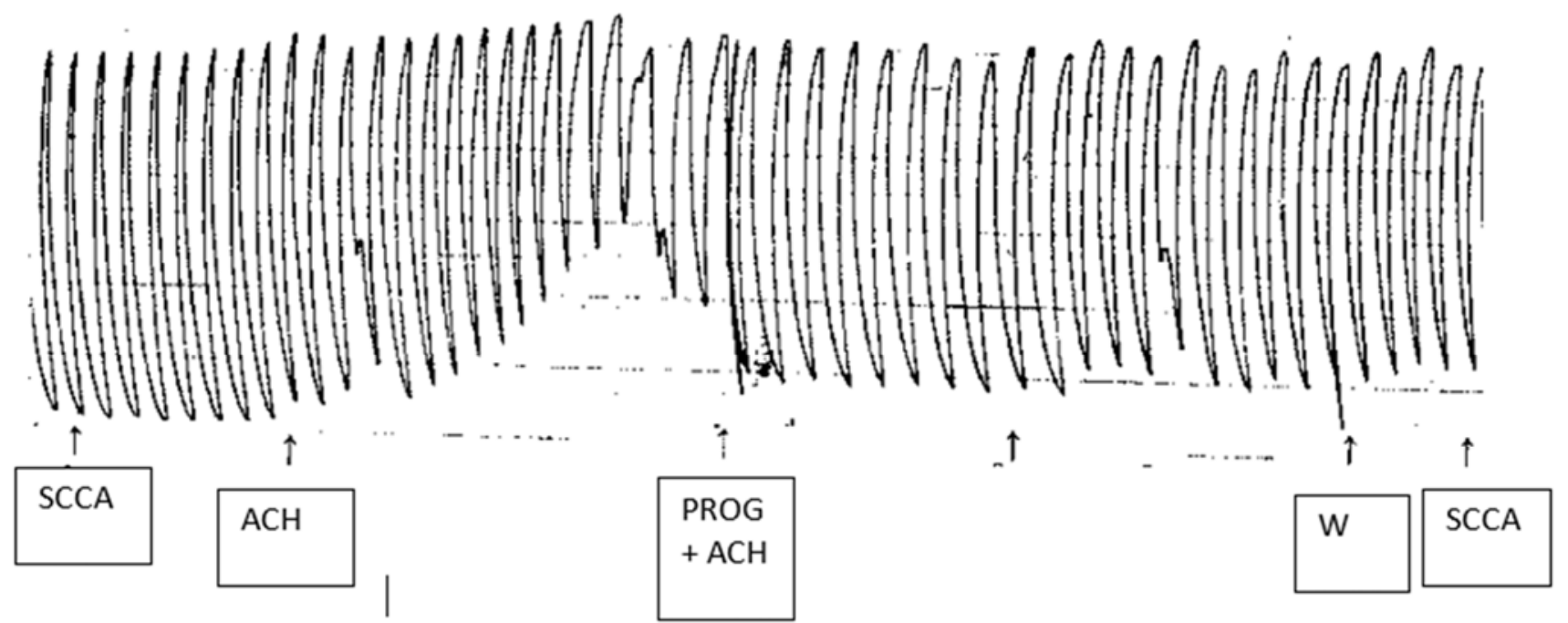

Figure 5. Show the effect of prog on ach induced contraction. 


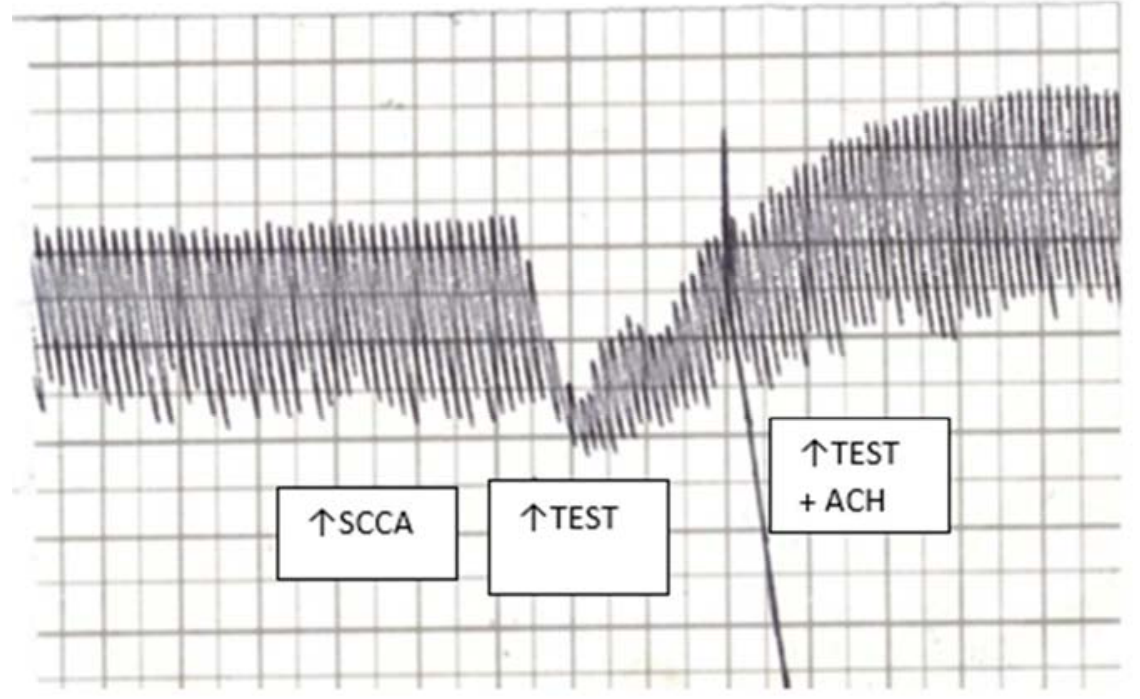

Figure 6. The Effect of TEST (Testosterone) and TEST + ACH on SCCA in male rats.

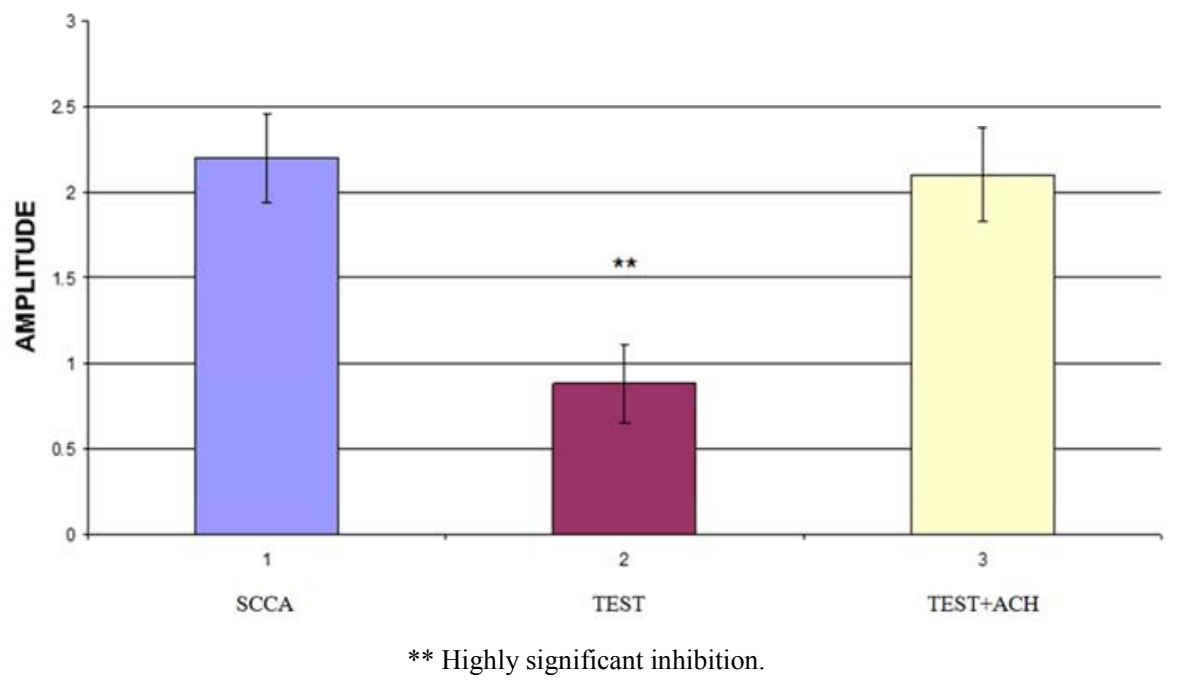

Figure 7. The Effect of TEST (Testosterone) and TEST+ACH on SCCA.

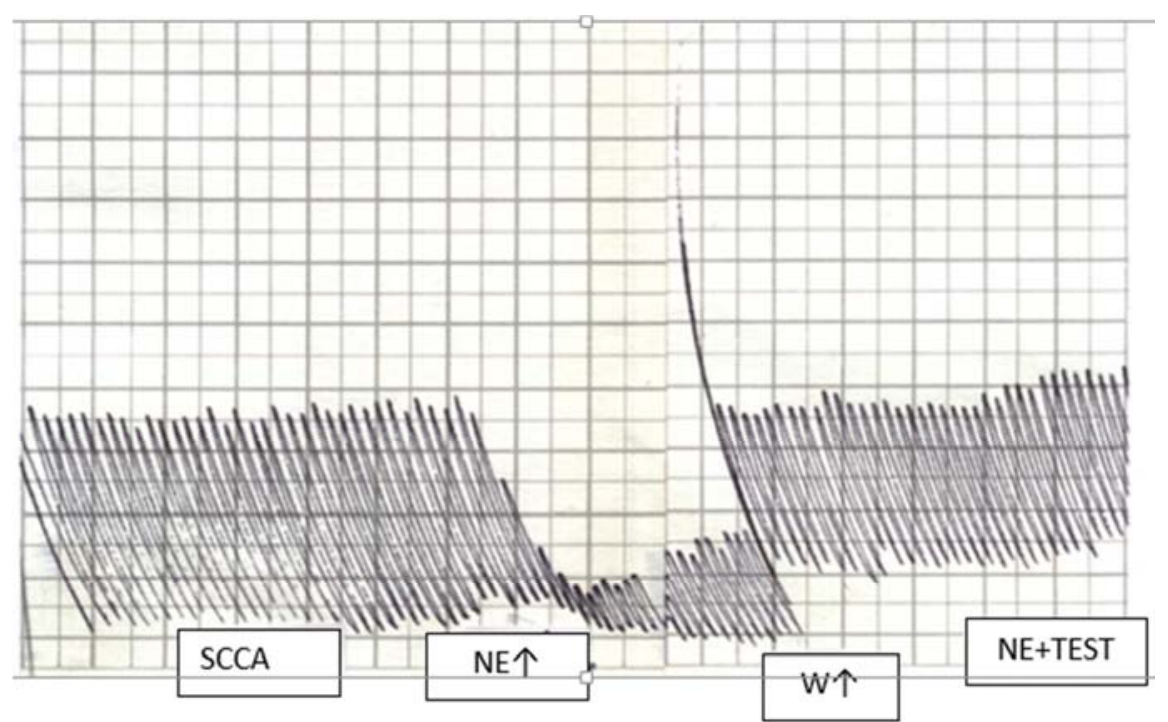

Figure 8. The Effect of NE and NE with TEST on amplitude of SCCA in Female rats. 


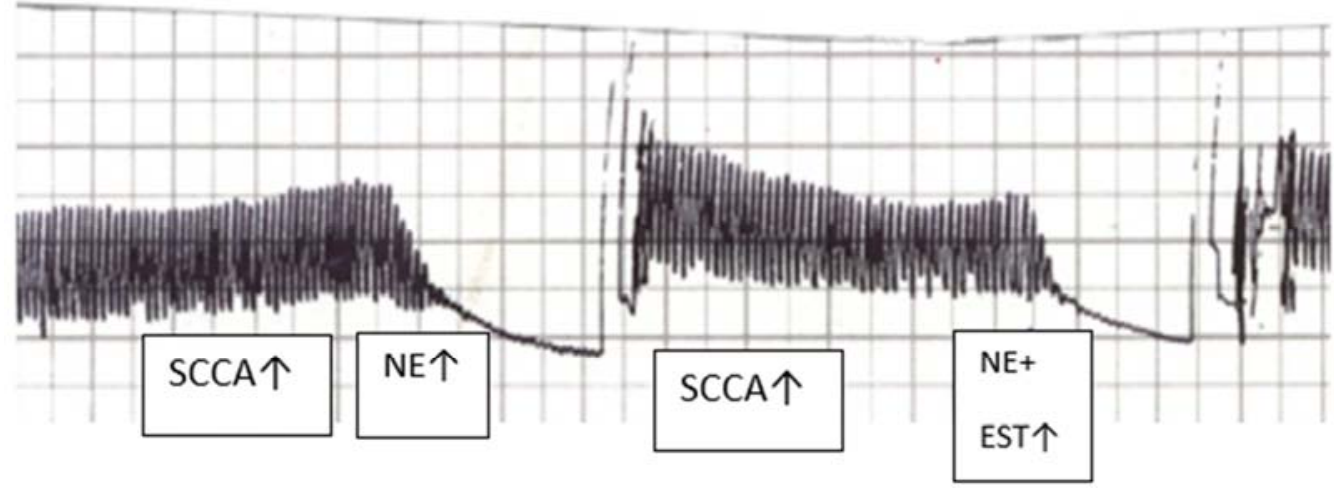

Figure 9. The effect of NE and NE+EST on SCCA in male rats.

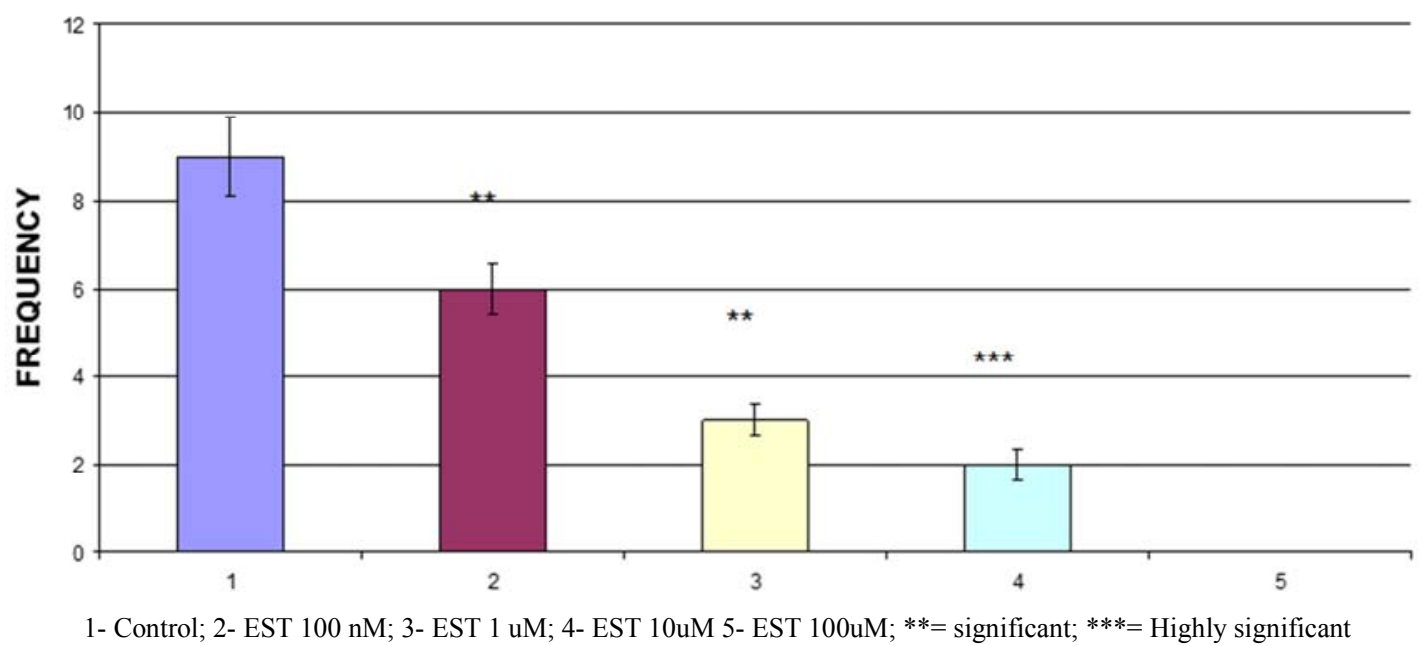

Figure 10. The Effect of different doses of EST on frequency of SCCA (in 10-minutes period).

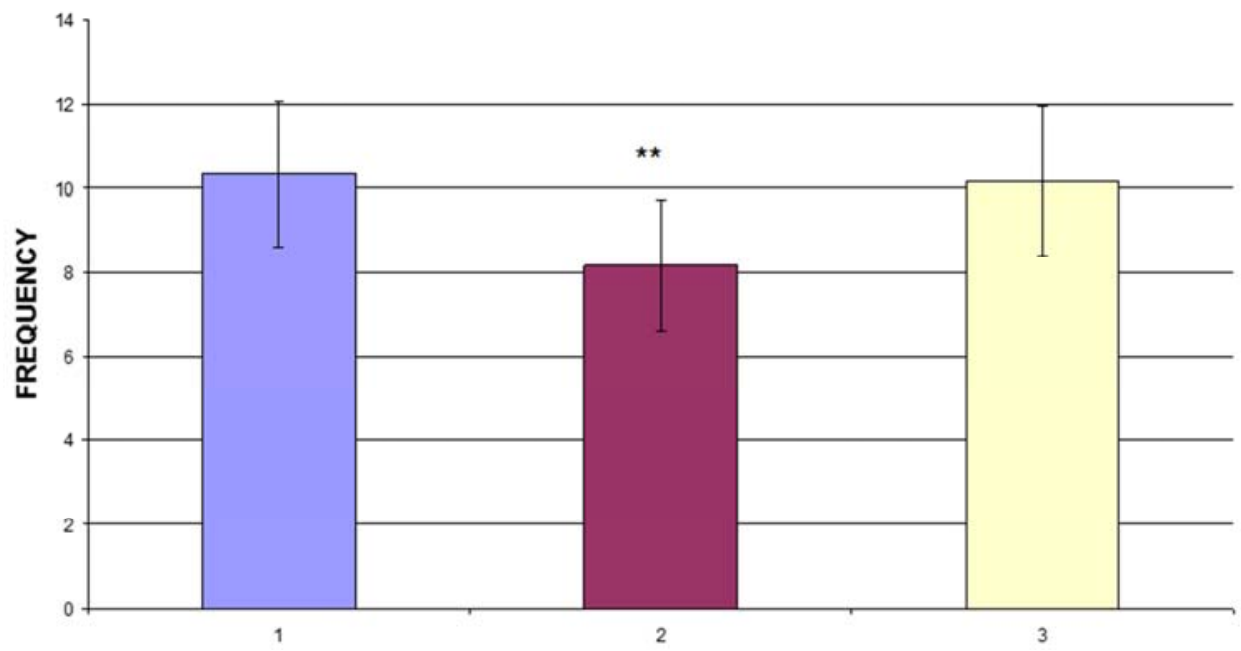

1- SCCA; 2- NE (NorEpinephrine); 3- NE+TEST

Figure 11. Effect of NE and NE with TEST on frequency of SCCA (in female rats).

\section{Discussion}

Irritable bowel syndrome (IBS) is the most common functional gastrointestinal disorder. A higher incidence of functional bowel disorders in females suggested a contributing effect of gonadal hormones. Therefore, the aim of the present study was to demonstrate the effect of gonadal hormones on colonic motility in rats.

In the present study, we found that EST has an inhibitory effect on SCCA in both sexes, whereas PROG inhibits SCCA only in females. EST also has a negative effect on Ach stimulation, but only in females. We also found that TEST 
inhibited SCCA in male rats. In females, TEST decreases the NE-induced inhibition on SCCA. Our findings are in agreement with Heitkemper and Bond who found that ovariectomized rats with chronic estrogen replacement showed an increased gastric basal contraction frequency [20]. The underlying mechanisms for these differences in gastrointestinal contractility between the sexes could be explained by chronic exposure to different gonadal hormones, but could also be genetically determined via inheritance of certain gender specific alleles. In our experiments on Albino rats, we found that EST and PROG decreased SCCA in females in a dosedependent manner. In male rats, EST and PROG led to a significant reduction of SCCA. A similar effect of EST was observed regarding ACH-induced colonic smooth muscle contractility in females. These findings indicate that acute administration of EST and PROG has an inhibitory effect on colonic contractility in rats in contrast to chronic exposure of female gonadal hormones to colon smooth muscle leading to hypercontractility. Different mechanisms are triggered by the acute and chronic application of hormones via non-genomic and genomic pathways [21]. EST has been shown to act on colonic smooth muscle via different pathways. The genomic effects involving the binding of EST to intracellular receptors with consecutive gene transcription and de novo protein synthesis have a latency of onset of 2-8 h. [21]. Several authors have described non-genomic pathways of EST associated with rapid effects via various second messengers and modulating ion channels on different cell types [22, 23]. Similarly, PROG also acts on intestinal smooth muscle cells via genomic and non-genomic pathways $[24,25]$. In our study, the non-genomic effects of PROG can explain the rapid action of PROG on colonic smooth muscle contractility. This rapid mechanism of action that does not require gene transcription has been confirmed in several studies $[26,27]$.

We also found that PROG inhibited significantly colonic contractility. This finding was confirmed by other studies [24, 27, and 28]. Some of these studies found that PROG rapidly and reversibly decreased calcium entry through voltage-sensitive calcium currents [24, 27]. Other studies like Xiao et al. described the non-genomic effect of PROG by a blockade of calcium release from intracellular stores without any effect on calcium influx [28]. These rapid non-genomic effects last for less than 60 minutes and are not seen in in vivo experiments where the cells are continuously exposed to PROG. This is due to a rapid desensitization of the cells as a result of prolonged exposure to PROG [26]. These findings could explain the controversy between the acute and chronic effects of PROG under physiological conditions. An explanation for the significant action of PROG on female colonic smooth muscle cells, but not on male cells could be attributed to the different distribution or number of PROG receptors in the colon of females compared to males. We confirmed in our study that EST has a significant inhibitory effect on SCCA. This finding was supported by Hogan et al., who found that EST decreased human colonic smooth muscle contractility [18]. Our results were also in agreement with Tang et al., [29] who showed similar results in colonic circular muscle of rats. Also, EST has been demonstrated to inhibit smooth muscle contractility in other tissues such as the gall bladder [30] esophagus [31] and detrusor [32, 33]. However, our results were in controversy with Bruce and Beshudi who found that EST enhanced gastrointestinal smooth muscle contractility but this controversy con be explained by the different method of EST administration where they used the chronic administration of EST in male rats.[34].

We also found that PROG inhibited SCCA in the form of significant reduction in Amplitude, frequency and basal tone. This inhibitory effect of PROG was supported by other studies on GIT [35-37]. In consistency with our findings, this rapid inhibitory effect has only been seen with high concentrations of PROG that do not occur in vivo [39]. However, our findings were in contrast with an in vivo study by Gonenne et al. who did not find any significant change in colonic transit by the withdrawal of PROG or EST [17]. This controversy could be explained by the desensitization of the non-genomic pathways by prolonged hormonal exposure under physiological conditions.

In our study, EST reduced the contractile action of $\mathrm{ACH}$ in females. This finding suggests that EST interferes with cholinergic (muscarinic) receptors. Muscarinic M2 and M3 receptors have been identified in rat colonic smooth muscle [40]. EST could influence the adenylyl cylclase activity triggered by the M2 receptor or interfere with mechanisms mediated by M3 such as the augmentation of phosphoinositide hydrolysis [41]. In our study we did not find any significant effect of EST on NE induced inhibition of colonic smooth muscle contractility but we found that PROG has a potentiating effect on NE induced inhibition of colonic smooth muscle contractility. EST leads to a suppression of beta-adrenoceptor mediated relaxation in the vascular smooth muscle without modifying the beta adrenoceptors binding characteristics [42]. We suggested that estrogen has a modulatory effect on NE induced changes in smooth muscle contractility. This suggestion is supported by Riemer et al., [43] who found that estrogen increases alphaadrenergic sensitivity in the myometrium, also without changes in the alpha-receptors. Thus, EST does not seem to have a direct influence on NE receptors.

We also found that TEST has a significant reduction of SCCA only in male Albino rats, but not in females. Our results are in controversy with Gonzáles-Montelongo et al. who found that physiological concentrations (10nmol) of testosterone had a stimulating effect on spontaneous contractility in longitudinal colonic smooth muscle of male Swiss CD1 mice [44]. The reason for the contradictory results could be a dose dependent action of TEST: In our study, we used supraphysiological concentrations. Similar to EST, TEST also acts via genomic (requiring gene transcription) and quick non-genomic pathways [45, 46]. Our results showed no effect of TEST on ACh-induced contractions in male rats. Furthermore, we found an inhibitory effect of TEST on NE-induced relaxation in female animals. 


\section{Conclusion}

Our study showed that acute administration of estradiol decreased SCCA in both sexes whereas progesterone leads to a decrease in SCCA only in females. The ACH-triggered increase of colonic contractile activity is reduced by estradiol only in females. We also found that Testosterone has a significant inhibitory effect on SCCA only in males, no effect on the $\mathrm{ACH}$-induced CCA in males whereas the NE-induced inhibition of SCCA is reduced in females. These findings support our suggestion of a strong effect of gonadal hormones on colonic contractile activity and may contribute to the better understanding of the observation that women seem to be more prone to develop Irritable Bowel Syndrome. The results of our study also suggested that gonadal hormones have an acute local effect on CCA, which could be a step discovery of new therapeutic agents in IBS. Further studies are recommended to demonstrate the exact mechanisms and pathways underlying our present results.

\section{References}

[1] Drossman DA, Camilleri M, Mayer EA, Whitehead WE. AGA technical review on irritable bowel syndrome. Gastroenterology 2002; 123 (6): 2108-31. Lacy BE, Mearin F, Chang L et al. Bowel disorders. Gastroenterology 2016; 150 (6): 1393-1407.

[2] Wilson S, Roberts L, Roalfe A, Bridge P, Singh S. Prevalence of irritable bowel syndrome: a community survey. $\mathrm{Br} J \mathrm{Gen}$ Pract 2004; 54 (504): 495-502.

[3] Brandt LJ, Chey WD, Foxx-Orenstein AE, et al. An evidencebased position statement on the management of irritable bowel syndrome. Am J Gastroenterol 2009; 104 Suppl 1: S1-35.

[4] Meleine M, Matricon J. Gender-related differences in irritable bowel syndrome: Potential mechanisms of sex hormones. World J Gastroenterol 2014; 20 (22): 6725-43.

[5] Whitehead WE, Holtkotter B, Enck P, et al. Tolerance for rectosigmoid distention in irritable bowel syndrome. Gastroenterology 1990; 98 (5 Pt 1): 1187-92. Chey WD, Kurlander J, Eswaran S. Irritable bowel syndrome: a clinical review. JAMA 2015; 313 (9): 949-58.

[6] Serra J, Azpiroz F, Malagelada JR. Impaired transit and tolerance of intestinal gas in the irritable bowel syndrome. Gut 2001; 48 (1): 14-9.

[7] Bouin M, Plourde V, Boivin M, et al. Rectal distention testing in patients with irritable bowel syndrome: sensitivity, specificity, and predictive values of pain sensory thresholds. Gastroenterology 2002; 122 (7): 1771- 7.

[8] Liebregts T, Adam B, Bredack C, et al. Immune activation in patients with irritable bowel syndrome. Gastroenterology 2007; 132 (3): 913-20.

[9] Chadwick VS, Chen W, Shu D, et al. Activation of the mucosal immune system in irritable bowel syndrome. Gastroenterology 2002; 122 (7): 1778-83.

[10] Snape WJ, Jr., Carlson GM, Cohen S. Colonic myoelectric activity in the irritable bowel syndrome. Gastroenterology
1976; 70 (3): 326-30.

[11] Kellow JE, Gill RC, Wingate DL. Prolonged ambulant recordings of small bowel motility demonstrate abnormalities in the irritable bowel syndrome. Gastroenterology 1990; 98 (5 Pt 1): 1208-18.

[12] Chang L, Heitkemper MM. Gender differences in irritable bowel syndrome. Gastroenterology 2002; 123 (5): 1686-1701.

[13] 28. Karantanos T, Markoutsaki T, Gazouli M, Anagnou NP, Karamanolis DG. Current insights in to the pathophysiology of Irritable Bowel Syndrome. Gut Pathog 2010; 2 (1): 3.

[14] Cui N, Wu BP, Wu SZ. [Association of peripheral blood estradiol, progesterone and testosterone levels with irritable bowel syndrome]. Nan Fang Yi Ke Da Xие Xие Bao 2006; 26 (3): $367-8$.

[15] Heitkemper MM, Chang L. Do fluctuations in ovarian hormones affect gastrointestinal symptoms in women with irritable bowel syndrome? Gend Med 2009; 6 Suppl 2: 152-67.

[16] Ryan JP, Bhojwani A. Colonic transit in rats: effect of ovariectomy, sex steroid hormones, and pregnancy. Am J Physiol 1986; 251 (1 Pt 1): G46- 50.

[17] Gonenne J, Esfandyari T, Camilleri M, et al. Effect of female sexhormone supplementation and withdrawal on gastrointestinal and colonic transit in postmenopausal women. Neurogastroenterol Motil 2006; 18 (10): 911-8.

[18] Hogan AM, Kennelly R, Collins D, Baird AW, Winter DC. Oestrogen inhibits human colonic motility by a non-genomic cell membrane receptor-dependent mechanism. $\mathrm{Br} J$ Surg 2009; 96 (7): 817-22.

[19] Domali, E.; asprodini, E.; Molyvads, P. A. and Messinis, I. E.: In Vitro effects of Endothelin-1 on the contractility of myometrium obtained from pre- and postmenopausal women. J Endocrinol, 2001; 168 (1): 153-162.

[20] Heitkemper MM, Bond EF. Gastric motility in rats with varying ovarian hormone status. West J Nurs Res 1995; 17 (1): $9-19$.

[21] Doolan CM, Harvey BJ. A Galphas protein-coupled membrane receptor, distinct from the classical oestrogen receptor, transduces rapid effects of oestradiol on $\left[\mathrm{Ca}^{2+}\right] \mathrm{i}$ in female rat distal colon. Mol Cell Endocrinol 2003; 199 (1-2): 87-103.

[22] Sylvia VL, Walton J, Lopez D, Dean DD, Boyan BD, Schwartz Z. 17 betaestradiol- BSA conjugates and 17 betaestradiol regulate growth plate chondrocytes by common membrane associated mechanisms involving PKC dependent and independent signal transduction. J Cell Biochem 2001; 81 (3): 413-29.

[23] Falkenstein E, Wehling M. Nongenomically initiated steroid actions. Eur J Clin Invest 2000; 30 Suppl 3: 51-4.

[24] Oh ST, Yedidag E, Bielefeldt K. Differential effects of progesterone and its analogues on the contractility of the murine jejunum in vitro. $J$ Surg Res 1998; 75 (1): 1-5.

[25] Braverman DZ, Johnson ML, Kern F, Jr. Effects of pregnancy and contraceptive steroids on gallbladder function. $N$ Engl $J$ Med 1980; 302 (7): 362-4.

[26] Xiao ZL, Pricolo V, Biancani P, Behar J. Role of progesterone signaling in the regulation of G-protein levels in female chronic constipation. Gastroenterology 2005; 128 (3): 667-75. 
[27] Bielefeldt K, Waite L, Abboud FM, Conklin JL. Nongenomic effects of progesterone on human intestinal smooth muscle cells. Am J Physiol 1996; 271 (2 Pt 1): G370-6.

[28] Xiao ZL, Cao W, Biancani P, Behar J. Nongenomic effects of progesterone on the contraction of muscle cells from the guinea pig colon. Am J Physiol Gastrointest Liver Physiol 2006; 290 (5): G1008-15.

[29] Tang YR, Yang WW, Wang Y, Gong YY, Jiang LQ, Lin L. Estrogen regulates the expression of small-conductance $\mathrm{Ca}^{2+}$ activated $\mathrm{K}^{+}$channels in colonic smooth muscle cells. Digestion 2015; 91: 187-96.

[30] Cirillo DJ, Wallace RB, Rodabough RJ, et al. Effect of estrogen therapy on gallbladder disease. Jama 2005; 293 (3): 330-9.

[31] Everson GT. Gastrointestinal motility in pregnancy. Gastroenterol Clin North Am 1992; 21 (4): 751-76.

[32] Valeri A, Brain KL, Young JS, Sgaragli G, Pessina F. Effects of 17betaoestradiol on rat detrusor smooth muscle contractility. Exp Physiol 2009; 94 (7): 834-46.

[33] Dambros M, van Koeveringe GA, Bast A, van Kerrebroeck PE. Relaxant effects of estradiol through non-genomic pathways in male and female pig bladder smooth muscle. Pharmacology 2004; 72 (2): 121-7.

[34] Bruce LA, Beshudi FM. Increased gastrointestinal motility in vitro following chronic estrogen treatment in male rats. Proc Soc Exp Biol Med 1981; 166 (3): 355-9.

[35] Li CP, Ling C, Biancani P, Behar J. Effect of progesterone on colonic motility and fecal output in mice with diarrhea. Neurogastroenterol Motil 2012; 24: 392-e174.

[36] Wang F, Zheng TZ, Li W, Qu SY, He DY. Action of progesterone on contractile activity of isolated gastric strips in rats. World J Gastroenterol 2003; 9 (4): 775-8.

[37] Shah S, Nathan L, Singh R, Fu YS, Chaudhuri G. E2 and not P4 increases NO release from NANC nerves of the gastrointestinal tract: implications in pregnancy. Am J Physiol Regul Integr Comp Physiol 2001; 280 (5): R1546-54.

[38] Scott AP, Sheldrick EL, Flint AP. Measurement of 17 alpha, 20 betadihydroxy- 4-pregnen-3-one in plasma of trout (Salmo gairdneri Richardson): seasonal changes and response to salmon pituitary extract. Gen Comp Endocrinol 1982; 46 (4): 444-51.

[39] Elhadd TA, Neary R, Abdu TA, et al. Influence of the hormonal changes during the normal menstrual cycle in healthy young women on soluble adhesion molecules, plasma homocysteine, free radical markers and lipoprotein fractions. Int Angiol 2003; 22 (3): 222-8.

[40] Zhang L. Muscarinic receptors in developing rat colon. Eur J Pharmacol 1996; 304 (1-3): 211-9.

[41] Zhang LB, Buxton IL. Muscarinic receptors in canine colonic circular smooth muscle. II. Signal transduction pathways. Mol Pharmacol 1991; 40 (6): 952-9.

[42] Yamaguchi K, Honda H, Tamura K, Kogo H. Possible mechanisms for the suppressing action of 17beta-estradiol on beta-adrenoceptormediated vasorelaxation in rat aorta. Eur $J$ Pharmacol 2001; 427 (1): 61-7.

[43] Riemer RK, Goldfien A, Roberts JM. Rabbit myometrial adrenergic sensitivity is increased by estrogen but is independent of changes in alpha adrenoceptor concentration. $J$ Pharmacol Exp Ther 1987; 240 (1): 44-50.

[44] Gonzalez-Montelongo MC, Marin R, Gomez T, MarreroAlonso J, Diaz M. Androgens induce nongenomic stimulation of colonic contractile activity through induction of calcium sensitization and phosphorylation of LC20 and CPI-17. Mol Endocrinol 2010; 24 (5): 1007-23.

[45] Simoncini T, Genazzani AR. Non-genomic actions of sex steroid hormones. Eur J Endocrinol 2003; 148 (3): 281-92.

[46] Boonyaratanakornkit V, Edwards DP. Receptor mechanisms mediating non-genomic actions of sex steroids. Semin Reprod Med 2007; 25 (3): 139-53. 